\title{
Prognostic significance of EGFR and Her-2 in oral cavity cancer in betel quid prevalent area
}

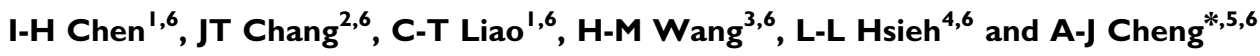 \\ 'Department of Otorhinolaryngology, Section of Head and Neck Surgery, Chang Gung Memorial Hospital,Taoyuan, Taiwan; ${ }^{2}$ Department of Radiation \\ Oncology, Chang Gung Memorial Hospital, Taoyuan, Taiwan; ${ }^{3}$ Division of Hematology/Oncology, Department of Internal Oncology, Chang Gung \\ Memorial Hospital, Taoyuan, Taiwan; ${ }^{4}$ Department of Public Health, Chang Gung University, Taoyuan, Taiwan; ${ }^{5}$ School of Medical Technology, Chang \\ Gung University, Taoyuan, Taiwan; ${ }^{6}$ Taipei Chang Gung Head and Neck Oncology Group, Taoyuan 333, Taiwan
}

\begin{abstract}
Although several studies have found overexpression of epidermal growth factor receptor (EGFR) proteins EGFR and Her-2 in head and neck cancers, the clinical relevance of the finding varies. We examined the expression and clinical association of these molecules with oral squamous cell carcinoma in an area where betel chewing is prevalent. EGFR and Her-2 proteins were measured in 59 paired (grossly normal and cancer) tissues by an enzyme immunoassy method. The cutoff value for gene overexpression was defined as the level of mean expression in normal tissue plus two s.d. A total of $59 \%$ of the patients consumed alcohol, $90 \%$ smoked tobacco, and $90 \%$ chewed betel quid. Of the patients assayed, 34 (58\%) and 24 (4l\%) had EGFR and Her-2 overexpression, with average 3.5and I.5-fold elevations. EGFR overexpression has been shown to be statistically associated with T stage, N stage, overall TMN stage, primary tumour depth, lymph node extra-capsular spread, and poor survival. Her-2 overexpression, however, did not demonstrate a similar association with clinicopathological parameters or therapeutic outcome. On multivariant analysis, EGFR overexpression $(P=0.04 \mathrm{I})$ and $\mathrm{N}$ stage $(P=0.024)$ were the only independent factors for overall survival. These results indicate that the molecular targeting therapy to EGFR may be a treatment for oral cavity cancer in the betel quid-chewing prevalent area.

British Journal of Cancer (2003) 89, 68I-686. doi:I0.1038/sj.bjc.660 I I7I www.bjcancer.com
\end{abstract}

(c) 2003 Cancer Research UK

Keywords: oral cancer; EGFR; Her-2; prognosis; betel quid

Squamous cell carcinoma (SCC) of the oral cavity is one of the most frequent cancers in the world (Vokes et al, 1993). This disease occurs much more frequently in males (Johnson, 1991). Epidemiologic studies show a strong association between its incidence and environmental carcinogens, especially the use of tobacco, alcohol, and betel quid (Franceschi et al, 1990; Ko et al, 1995; Hsieh et al, 2001). In Taiwan, the incidence of oral carcinoma is one of the highest in the world. The incidence of oral cavity cancer was 20 per million in our male population, comprising approximately $4-5 \%$ of all malignancies (Chen, 1987). Approximately $85 \%$ of all oral cavity cancer patients habitually use betel quid (Chong, 1966). The majority of oral carcinoma in Taiwan occurs in buccal mucosa (ICD145), which was relatively less common in Western populations (Daftary et al, 1991). Such geographical differences in incidence and cancer sites may result from exposure to different carcinogens, and possibly also from genetic predisposition.

The overall 5-year survival rate for patients with oral carcinoma is among the lowest of the major cancers and has not changed during the past two decades (Parker et al, 1996). The standard treatment for patients with this cancer is surgery, radiation, or multiple modalities for patients at high risk (Clayman et al, 1996). Although standard care is frequently initially successful in earlystage cancer (stage I or II), disease relapses still occur in about

\footnotetext{
*Correspondence: Dr A-J Cheng, Department of Medical Technology, Chang Gung University, 259 Wen-Hwa Ist Road, Taoyuan 333, Taiwan; E-mail: ajchen@mail.cgu.edu.tw

Received 4 February 2003; revised 13 May 2003; accepted 5 June 2003
}

$20-30 \%$, particularly local tumour or lymph node recurrence (Vikram, 1994; Clayman et al, 1996). For patients with advanced oral carcinoma (stage III or IV), standard therapy is far less successful. The recurrent rate in advanced stage is approximately $50-60 \%$ and distant metastasis is $20-35 \%$ (Clayman et al, 1996). Even if there is a good treatment response, patients with advanced disease often suffer substantial functional and cosmetic morbidity, which decreases the quality of life. The identification of prognostic factors that may affect disease outcome may lead to improvements in adjuvant systemic therapy and better control of the disease.

The tyrosine kinase receptor, epidermal growth receptor (EGFR) family proteins EGFR and Her-2 have been reported to be overexpressed in many cancers. They are often associated with a poor prognosis, suggesting that they are potential molecular targets for anticancer therapy. This family of proteins consists of four closely related transmembrane receptors, including EGFR (erbB1), HER-2 (erbB2), HER-3 (erbB3), and HER-4 (erbB-4) (Olayioye et al, 2000; Simon, 2000). Several ligands, such as EGF and amphiregulin, bind to EGFR, whereas there is no known highaffinity ligand binding to Her-2. However, both EGFR and Her-2 interact with other members of the family by heterodimerisation, resulting in activation of their intrinsic kinase activity (Olayioye et al, 2000). Overexpression of EGFR and Her-2 have been reported to be associated with higher grades or reduced survival in a variety of cancers, including breast, colorectal, and head and neck cancers (for a review, see Klijn et al, 1992; Salomon et al, 1995). Several molecular therapeutic agents against EGFR or Her-2, such as Cetuximab and Herceptin, have been studied in clinical trials (Colomer et al, 2001; Robert et al, 2002). 
Although several studies have found overexpression of EGFR and Her-2 in head and neck cancers, the clinical relevance of the finding varies. For example, Storkel et al (1993) found that overexpression of EGFR was associated with shortened survival, but Werkmeister et al (2000) reported that Her-2 was strongly associated with survival. Christensen et al (1995) and Khan et al, (2002) could not find significant correlation of either EGFR or Her2 with clinicopathological features or prognosis; however, Bei et al (2001) and Xia et al (1999) found colocalisation of both molecules in oral cancer tissues and the combined use of these molecules is a stronger predictor for the cancer prognosis. We therefore designed this study to investigate EGFR and Her-2 in paired grossly normal and cancerous tissues from squamous cell carcinoma of oral cavity patients. Our aims were to determine their levels of expression and see if these levels correlated with clinicopathological variables, and if they were useful prognostically.

\section{MATERIALS AND METHODS}

\section{Patients, tissues and cells}

Fifty-nine consecutive patients seen in 1999 at the Otorhinolaryngology or Head and Neck Surgery clinics at Chang Gung Memorial Hospital (Taoyuan, Taiwan) were enrolled for the study. Written informed consent was obtained from all patients participating in this study. A questionnaire was filled out by each patient before the first clinical visit investigating whether or not the patient was a habitual betel net chewer (daily chewer), cigarette smoker (daily smoker), and/or regular alcohol drinker (daily drinker). The standard treatment was radical surgery for earlystage patients and adjuvant radiotherapy for patients with intermediate risk, such as a close margin or lymph node metastases. Concomitant chemoradiotherapy was given in patients with lymph node metastases and extracapsular spread (ECS). All cancers were histologically graded as well differentiated, moderately differentiated, or poorly differentiated, according to the World Health Organization (WHO) classification (Shanmugaratnam, 1991). For each sample, the presence of bone or nerve invasion, lymphatics, blood vessels, tumour depth, and the presence or absence of lymph node ECS were specifically recorded. Tumour pathological staging was classified according to the AJCC system (Fleming et al, 1998). Biopsies of cancerous and grossly normal mucosa tissue were obtained from each subject before chemo- or radiotherapy. A portion of each tissue sample was stored in liquid nitrogen until use for molecular assay. An oral cancer cell line OC2 (Wong et al, 1990) was used as a positive control. OC2 cells were grown at $37^{\circ} \mathrm{C}, 5 \% \mathrm{CO}_{2}$ in RPMI medium containing $10 \%$ fetal bovine serum and antibiotics $\left(100 \mathrm{U} \mathrm{ml}^{-1}\right.$ penicillin, $100 \mathrm{Uml}^{-1}$ streptomycin, and $0.25 \mu \mathrm{g} \mathrm{ml}^{-1}$ amphotericin B).

\section{Extraction of cellular proteins}

The investigators were blinded as to the source and type of tissue being assayed. Tissue samples $(\sim 50 \mathrm{mg})$ were homogenised in $300 \mu \mathrm{l}$ of a lysis buffer (10 mM Tris-HCI, pH 7.5, $1 \mathrm{~mm} \mathrm{MgCl}_{2}, 1 \mathrm{~mm}$ EGTA, 0.5\% CHAPS (Pharmacia Ontario, Canada), 10\% glycerol, $5 \mathrm{~mm}$ mercaptoethanol, and $0.1 \mathrm{~mm}$ phenylmethylsulphonyl fluoride (PMSF) in Kontes tubes with matching pestles rotated at 450 r.p.m. After $30 \mathrm{~min}$ at $4^{\circ} \mathrm{C}$, the lysate was centrifuged at 15000 r.p.m. for $30 \mathrm{~min}$ at $4^{\circ} \mathrm{C}$. The supernatants of the protein extracts were used for the EGFR and Her-2 ELISA assay. The protein concentration of each tissue sample was determined using Coomassie protein assay reagent (Pierce).

\section{Determination of EGFR and Her-2 protein levels}

An enzyme-linked immunosorbent assay (ELISA) was used to detect tissue EGFR and Her-2 protein expression. The ELISA kits were purchased from CalBiochem Inc. (CA, USA). A total of $10 \mu \mathrm{g}$ cellular protein was used in each assay, performed according to the manufacturer's protocol. All samples were analysed in duplicate and the average of the two was recorded. To define the relative expression of EGFR or Her-2, both cancer tissue and the normal counterpart samples were assayed. The cutoff value for gene overexpression was defined as the level of mean plus two s.d. in the normal tissue expression values, and was designated as one-fold of overexpression.

\section{Statistical analysis}

The Pearson $\chi^{2}$ test was used to look for the association between EGFR or Her-2 expression and clinicopathological parameters, including tumour extent ( $\mathrm{T}, \mathrm{N}$, and overall stage) and the pathological findings (degree of differentiation, tumour depth, or ECS). For prognostic factors analysis, the Kaplan-Meier method was used for single-variant analysis and the Cox logistic regression model was used for multivariant analysis. All $P$-values presented were two-sided, and the significance level was set at $<0.05$.

\section{RESULTS}

\section{Patient characteristics}

The patient characteristics are summarised in Table 1. Their median age was 48.0 years, ranging from 31 to 78 , and all were male. A total of $59 \%$ of the patients consumed alcohol, $90 \%$ smoked tobacco, and $90 \%$ chewed betel quid. Cancers included 24 (41\%) in the buccal mucosa, 18 (31\%) in the tongue, and $17(29 \%)$ in other sites. All cancers were SCC, with 20 (34\%) well differentiated, $33(56 \%)$ moderately differentiated, and six $(10 \%)$ poorly differentiated. The disease staging is summarised in Table 2.

Table I Characteristics of patients with oral cancer

\begin{tabular}{lcc}
\hline Characteristic & Number & Percentage (\%) \\
\hline Total & 59 & 100 \\
Sex & & \\
$\quad$ Female & 0 & 0 \\
$\quad$ Male & 59 & 100 \\
Age & & \\
$\quad \leqslant 40$ years & 13 & 22 \\
$41-60$ years & 31 & 53 \\
$\quad>60$ years & 15 & 25 \\
Habits & & 59 \\
Alcohol drinking & 35 & 90 \\
Smoking & 53 & 90 \\
Betel quid chewing & 53 & 41 \\
Cancer site & & 31 \\
Buccal mucosa & 24 & 29 \\
Tongue & 18 & 34 \\
Others & 17 & 56 \\
Cancer histological grade & & 10 \\
$\quad$ Mell differentiated & 20 & \\
Poderately differentiated & 33 & \\
Poorly differentiated & 6 &
\end{tabular}

Table 2 Tumour and node stage distribution

\begin{tabular}{lccccc}
\hline Stage & T1 & T2 & T3 & T4 & Total \\
\hline N0 & 7 & 15 & 4 & 11 & 37 \\
NI & 0 & 2 & 0 & 3 & 5 \\
N2 & 0 & 7 & 5 & 5 & 17 \\
Total & 7 & 24 & 9 & 19 & 59 \\
\hline
\end{tabular}


Of the 59 patients, seven (12\%) had stage I disease (T1N0), 15 (25\%) had stage II (T2N0), six (10\%) had stage III (T3N0, T2N1), and had $31(53 \%)$ stage IV (T4N0, T4N1, T2N2, T3N2, T4N2).

\section{The distribution of EGFR and Her-2 in oral cancer tissues}

The relative expression of EGFR and Her-2 in all 59 patients were examined and plotted in Figure 1. Similar results were obtained when we assayed EGFR and Her-2 levels using different sites of the same tumour. As shown in the Figures, EGFR was overexpressed in two (3\%) normal mucosa tissues and $34(58 \%)$ cancer tissues. Similarly, Her-2 was overexpressed in one (2\%) normal tissue and $24(41 \%)$ cancer tissues. Compared to all normal samples, the average expression of EGFR in cancer tissue was 3.48-fold, with an s.d. of 2.01, while the average expression of Her-2 was 1.51-fold, with an s.d. of 0.45 . Thus, although the levels of both EGFR and Her-2 expression differed significantly between normal and cancer tissues $(P<0.001)$, EGFR had greater overexpression than Her-2 on average in all the cancer patients. The distribution of EGFR and Her-2 expression in the 59 oral cancer tissues is summarised in Table 3. Of the patients, 17 (29\%) had normally expressed in both molecules, 16 (27\%) had overexpressed in both molecules, and 26 (44\%) had overexpressed in either molecule. EGFR and Her-2 were not significantly coexpressed $(P=0.245)$.

A

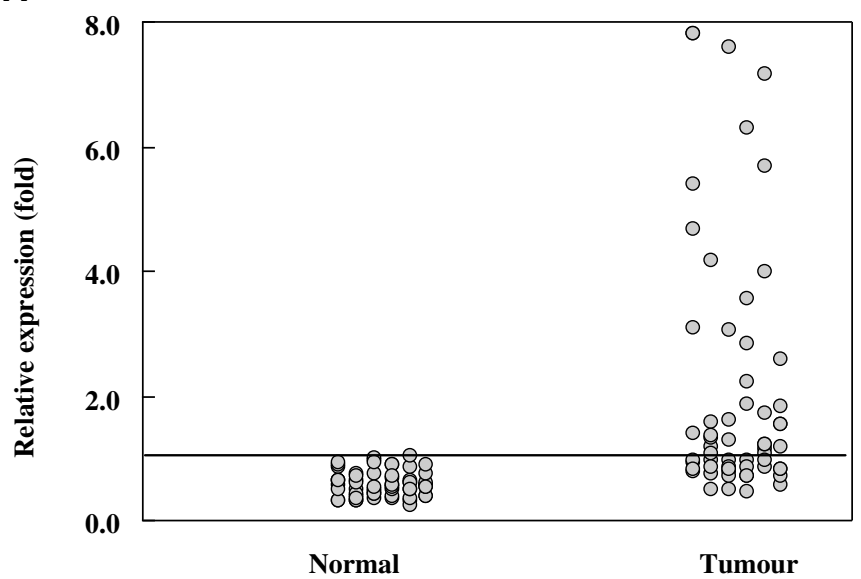

B

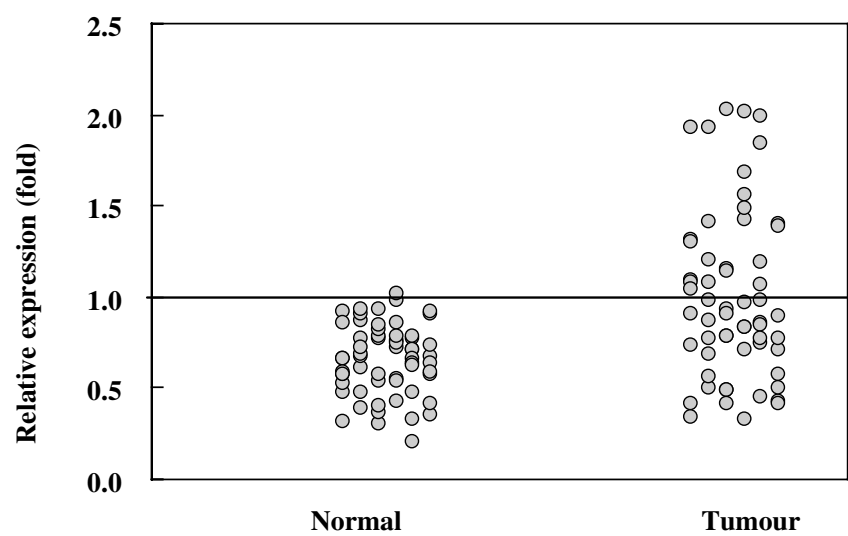

Figure I Relative expression of Her-2 and EGFR. (A) Relative expression of EGFR (A) and Her-2 (B) in normal and cancer tissue samples. The horizontal bar in the figure indicates the cut-off value (designated as one-fold)
Table 3 EGFR and Her-2 overexpression in oral cancer tissues

\begin{tabular}{lccc}
\hline & \multicolumn{3}{c}{ EGFR overexpression } \\
\cline { 2 - 4 } Her-2 overexpression & No & Yes & Total \\
\hline No & 17 & 18 & 35 \\
Yes & 8 & 16 & 24 \\
Total & 25 & 34 & 59 \\
\hline
\end{tabular}

\section{Correlation of EGFR or Her-2 with clinicopathological parameters}

The correlations of the expression levels of EGFR or Her-2 with clinicopathological parameters are shown in Table 4. As shown in the table, significant correlations were found between EGFR expression and tumour extent ( $\mathrm{T}$ stage) $(P=0.010)$, lymph node status (N stage) $(P=0.019)$, clinical overall stage $(P=0.002)$, tumour depth $(P=0.035)$, and ECS of lymph node $(P=0.025)$. However, there was no association between Her-2 expression with cancer stage or any other clinicopathological parameters. The results indicate that EGFR has an association with the aggressiveness of oral cancer.

Evaluation of possible prognostic factors associated with oral cancer

As shown in Table 5, for the 2-year survival, there were significant correlations with $\mathrm{N}$ stage $(P=0.000)$, overall stage $(P=0.008)$, tumour depth $(P=0.002)$, ECS of lymph node $(P=0.000)$, and the expression levels of EGFR $(P=0.001)$. To define the role of the above factors further, multivariant analysis was conducted and has been demonstrated in Table 6 . Lymph node metastasis $(P=0.024)$ and overexpression of EGFR $(P=0.041)$ were the only independent variables associated with poor survival, with a risk ratio of 4.22 for lymph node metastasis $(95 \% \mathrm{CI}=1.21-14.74)$, and 5.88 for EGFR overexpression $(95 \% \mathrm{CI}=1.07-32.31)$. The Kaplan-Meier overall survival curves related to EGFR overexpression are shown in the Figure 2.

\section{DISCUSSION}

In our study, we found EGFR and Her-2 to be differentially expressed in oral SCC. Consistent with other reports, we found that both EGFR and Her-2 were overexpressed in a subset of oral cancer patients (58 and $41 \%$, respectively). However, compared to Her-2, EGFR overexpression was more significant in terms of the expression level (3.5-fold vs 1.5-fold). Although these two molecules were coexpressed in some patients, this was not a statistically significant association $(P=0.245)$. A high level of EGFR, but not of Her-2, was strongly associated with tumour aggressiveness and poor survival.

Although some of our findings are consistent with other reports, we noted above the conflicting data produced by various authors. These differences may be due to differences in assay techniques. For example, most of the investigators used the immunohistochemistry method to examine protein expressions (Storkel et al, 1993; Xia et al, 1999; Bei et al, 2001; Khan et al, 2002), while we used the ELISA method to quantitatively analyse EGFR and Her-2 protein levels. The advantage of the immunohistochemistry method is the precise localisation of the protein molecules in cells. However, this method reported that data determined by microscopic examination may be influenced by the subjective assessment through different individuals. Although the ELISA technique is less used in clinical study, this method is also widely 
Table 4 Association of EGFR and Her-2 status with clinicopathological parameters

\begin{tabular}{|c|c|c|c|c|c|c|c|}
\hline \multirow[b]{2}{*}{ Parameter } & \multicolumn{4}{|c|}{ EGFR overexpression } & \multicolumn{3}{|c|}{ Her-2 overexpression } \\
\hline & $N$ & No(\%) & Yes(\%) & $P$-value & No(\%) & Yes(\%) & $P$-value \\
\hline \multicolumn{8}{|l|}{ T stage } \\
\hline $\mathrm{TI}-\mathrm{T} 2$ & 31 & $18(58)$ & $13(42)$ & \multirow[t]{2}{*}{0.010} & $17(55)$ & $14(45)$ & \multirow[t]{2}{*}{0.461} \\
\hline $\mathrm{T} 3-\mathrm{T} 4$ & 28 & $7(25)$ & $21(75)$ & & $18(64)$ & $10(36)$ & \\
\hline \multicolumn{8}{|l|}{ Nstage } \\
\hline$N=0$ & 37 & $20(54)$ & $17(46)$ & \multirow[t]{2}{*}{0.019} & $22(60)$ & $15(4 \mid)$ & \multirow[t]{2}{*}{0.978} \\
\hline$N>0$ & 22 & $5(23)$ & $17(77)$ & & $13(59)$ & $9(4 I)$ & \\
\hline \multicolumn{8}{|l|}{ Overall stage } \\
\hline $1-\|$ & 22 & $15(68)$ & $7(32)$ & \multirow[t]{2}{*}{0.002} & $12(55)$ & $10(46)$ & \multirow[t]{2}{*}{0.565} \\
\hline$\| I \mid-I V$ & 37 & $10(27)$ & $27(73)$ & & $23(62)$ & $14(38)$ & \\
\hline \multicolumn{8}{|l|}{ Differentiation } \\
\hline Well & 20 & $9(45)$ & I | (55) & \multirow[t]{3}{*}{0.852} & $13(65)$ & $7(35)$ & \multirow[t]{3}{*}{0.050} \\
\hline Moderate & 33 & $13(39)$ & $20(60)$ & & $16(49)$ & $17(52)$ & \\
\hline Poor & 6 & $3(50)$ & $3(50)$ & & $6(100)$ & $0(0)$ & \\
\hline \multicolumn{8}{|c|}{ Tumour depth $>10 \mathrm{~mm}$} \\
\hline No & 26 & $15(58)$ & II (42) & \multirow[t]{2}{*}{0.035} & $13(50)$ & $13(50)$ & \multirow[t]{2}{*}{0.196} \\
\hline Yes & 33 & $10(30)$ & $23(70)$ & & $22(67)$ & II (33) & \\
\hline \multicolumn{8}{|c|}{ ECS of lymph node } \\
\hline No & 43 & $22(51)$ & $21(49)$ & \multirow[t]{2}{*}{0.025} & $25(58)$ & $18(42)$ & \multirow[t]{2}{*}{0.762} \\
\hline Yes & 16 & $3(19)$ & $13(81)$ & & $10(66)$ & $6(38)$ & \\
\hline Total & 59 & $25(42)$ & $34(58)$ & & $35(59)$ & $24(4 I)$ & \\
\hline
\end{tabular}

Table 5 Univariant analysis of prognostic factors in oral cancer

\begin{tabular}{lccr}
\hline Parameter & Group & $\begin{array}{c}\text { 2-year survival } \\
\text { (week) }\end{array}$ & P-value \\
\hline T stage & TI-2/T3-4 & $73 / 22$ & 0.101 \\
N stage & NO-I/N2-3 & $80 / 22$ & $<0.001$ \\
Overall stage & I-I/III-IV & $86 / 51$ & 0.008 \\
Tumour depth $(\mathrm{mm})$ & $\leqslant 10 />10$ & $84 / 48$ & 0.002 \\
LN ECS & No/yes & $79 / 19$ & $<0.001$ \\
EGFR overexpression & $(-) /(+)$ & $88 / 45$ & 0.001 \\
Her-2 overexpression & $(-) /(+)$ & $64 / 62$ & 0.928 \\
\hline
\end{tabular}

Table 6 Multivariant analysis of prognostic factors in oral cancer

\begin{tabular}{lccc}
\hline Parameter & Risk ratio & $\mathbf{9 5 \%} \mathbf{~ C l}^{\mathbf{a}}$ & $\boldsymbol{P}$-value \\
\hline T stage & 0.781 & $0.22-2.36$ & 0.583 \\
N stage & 4.215 & $1.21-14.74$ & 0.024 \\
Overall stage & 0.601 & $0.009-4.16$ & 0.606 \\
Tumour depth & 3.854 & $0.87-17.16$ & 0.077 \\
ECS of lymph node & 1.083 & $0.52-3.07$ & 0.601 \\
EGFR overexpression & 5.882 & $1.07-32.31$ & 0.041 \\
Her-2 overexpression & 1.083 & $0.36-3.26$ & 0.888 \\
\hline
\end{tabular}

${ }^{\mathrm{a}} \mathrm{Cl}=$ confidence interval.

accepted to determine protein expression levels. Examples include using this technique in the studies of breast cancer, cervical cancer, lung cancer as well as head and neck cancer (Christensen et al, 1995; Pfeiffer et al, 1998; Contreras et al, 2002; Widschwendter et al, 2002). The key advantage of the ELISA method is to provide a quantitative result with relatively less bias. When comparing these two methods, Pfeiffer et al (1998) have reported that significant correlation was found in the quantification of EGFR or Her-2 levels between ELISA and immunohistochemical methods studied in the lung and in breast cancers. These studies suggest that comparable evaluation results may be obtained by using these two assay techniques.

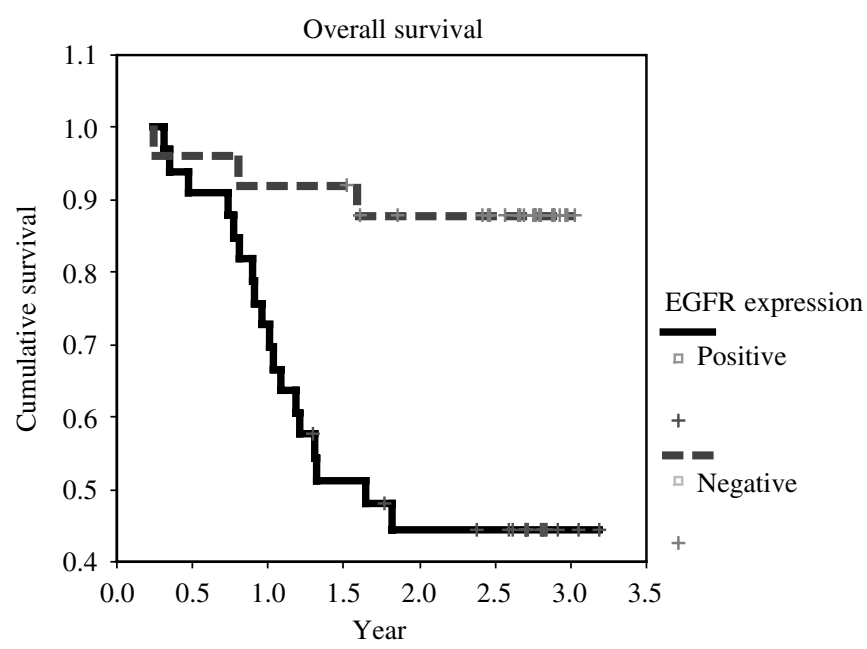

Figure 2 Kaplan-Meier overall survival curves according to EGFR overexpression.

Patient sampling is another variable between other studies and ours. Most investigators examine protein expressions between different tumour tissues (but no grossly normal counterpart tissues to compare) (Storkel et al, 1993; Xia et al, 1999; Bei et al, 2001; Khan et al, 2002). We analyse EGFR and Her-2 protein levels in the paired grossly normal mucosa and cancer tissues obtained from the same patients. These results will provide clearer information regarding the protein level changes after cellular transformation. Additionally, most other reports have evaluated populations in the West (Xia et al, 1999; Werkmeister et al, 2000; Bei et al, 2001), whereas ours focused on Southeast Asians. Since both carcinogen exposure (including betel quid chewing) and possible genetic predisposition vary between different geographic areas, the reported differences in EGFR or Her-2 expression may reflect different oral carcinogenic pathways in different populations. 
In the upper aerodigestive tract, significant exposure of the mucosa surface to the same carcinogens or stimulants (such as alcohol or cigarettes) may lead to a multitude of somatic changes that are susceptible to the development of multiple primary cancers. This phenomenon is called 'field cancerisation' (Slaughter et al, 1953). Recent molecular studies have shown that genetical alterations could be found in different areas of histological normal mucosa. Examples are mutations of the p53 tumour suppressor gene and deletions on the short arm of chromosome 3 (Li et al, 1994; Van Dyke et al, 1994). In our grossly normal mucosa tissues, which provide an internal control for comparing them with cancer tissues in the same patient, they may not represent true normal samples, particularly in patients who drink, smoke, and chew betel quids. However, in our present study, there is no statistical difference of the protein expression levels of EGFR and Her-2 between the normal tissues from patients with or without exposure to tobacco, alcohol, betel quid, or the combined exposure (data not shown). These results suggest that the 'filed' effect of EGFR and Her-2 molecules on the surrounding oral normal mucosa is minimum. Apparently, together with multiple injuries and cellular genetic mutations on a specific tissue, a process described as 'multistep carcinogenesis' will eventually transform the cell into malignant cancer (Vogelstein et al, 1998).

\section{REFERENCES}

Bei R, Pompa G, Vitolo D, Moriconi E, Ciocci L, Quaranta M, Frati L, Kraus $\mathrm{MH}$, Muraro R (2001) Co-localization of multiple ErbB receptors in stratified epithelium of oral squamous cell carcinoma. J Pathol 195: $343-348$

Chen CH (1987) An epidemiological study of oral squamous cell carcinoma in southern Taiwan. J Formosan Dent Assoc 10: 268-274

Chong KM (1966) Betel nut chewing and mouth cancer in Taiwan. Observation of the oral mucosa in the betel nut chewers. J Formosan Med Assoc 65: 79-85

Christensen ME, Engbaek F, Therkildsen MH, Bretlau P, Nexo E (1995) A sensitive enzyme-linked immunosorbent assay used for quantitation of epidermal growth factor receptor protein in head and neck carcinomas: evaluation, interpretations and limitations. Br J Cancer 72: 1487-1493

Clayman GL, Lippman SM, Laramore GE, Hong WK (1996) Head and neck cancer. In: Cancer Medicine, Holland JF, Frei E, Bast RC, Kufe DW, Morton DL, Weichselbaum R (eds) pp 1645-1709. Philadelphia: Williams and Wilkins

Colomer R, Shamon LA, Tsai MS, Lupu R (2001) Herceptin: from the bench to the clinic. Cancer Invest 19: $49-56$

Contreras DN, Cobos E, Lox CD (2002) Evaluation of the circulating fraction of the HER-2/neu oncogene in patients with cervical cancer. Eur J Gynaecol Oncol 23: 491-495

Daftary DK, Murti PR, Bhonsle RR, Gupta PC, Mehta FS, Pindborg JJ (1991) Risk factors and risk markers for oral cancers in high risk areas of the world. In: Oral Cancer: Detection of Patients and Lesions at Risk, Johnson NW (ed) pp 29-63. Cambridge: Cambridge University Press

Fleming ID, Cooper JS, Henson DE, Hutter RVP, Kennedy BJ, Murphy GP, O'Sullivan B, Sobin L, Yarbro JW (1998) AJCC Cancer Staging Manual, 5th edn. Lippincott: Williams Wilkins

Franceschi S, Talamini R, Barra S (1990) Smoking and drinking in relation to cancers of the oral cavity, pharynx, larynx, and esophagus in northern Italy. Cancer Res 50: 6502-6507

Hsieh LL, Wang PF, Chen IH, Liao CT, Wang HM, Chen MC, Chang JTC, Cheng AJ (2001) Characteristics of mutations in the p53 genes in oral squamous cell carcinoma associated with betel quid chewing and cigarette smoking in Taiwanese. Carcinogenesis 22: 1497-1503

Johnson NW (1991) A global view of the epidemiology of oral cancer. In: Oral Cancer: Detection of Patients and Lesions at Risk, Johnson NW (ed) pp 3-26. Cambridge: Cambridge University Press

Klijn JG, Berns PM, Schmitz PI, Foekens JA (1992) The clinical significance of epidermal growth factor receptor (EGF-R) in human breast cancer: a review on 5253 patients. Endocr Rev 13: 3-17

Khan AJ, King BL, Smith BD, Smith GL, DiGiovanna MP, Carter D, Haffty BG (2002) Characterization of the HER-2/neu oncogene by immunohis-
For a molecule to be a good candidate as a target for anticancer therapy, several criteria must be fulfilled. First, the protein should be overexpressed in cancer tissues compared to normal tissues. Second, overexpression of the protein should be associated with a poor prognosis, which suggests that manipulation of the protein may result in alteration of the prognosis. In this study, we found that the membrane protein EGFR had both these characteristics. Our results do not support similar targeting of the Her-2 protein, even though it is commonly overexpressed in oral SCC. Recently, targeting of EGFR as a molecular adjuvant therapy has been clinically tried in head and neck cancer (Shin et al, 2001; Robert et al, 2002). This study provides a fundamental knowledge base, suggesting that targeting this molecule might be useful in betel quid-associated oral cancers (Shin et al, 2001).

\section{ACKNOWLEDGEMENTS}

This work was supported by National Science Council Research Grant NSC89-2314-B-182A-088-M08 of Taiwan and Chang Gung Medical Research Grant CMRP869. We thank Mary Jeanne Buttrey, $\mathrm{MD}$ for critical reading and correction of the manuscript. tochemical and fluorescence in situ hybridization analysis in oral and oropharyngeal squamous cell carcinoma. Clin Cancer Res 8: 540-548

Ko YC, Huang YL, Lee CH, Chen MJ, Lin LM, Tsai CC (1995) Betel quid chewing, cigarette smoking and alcohol consumption related to oral cancer in Taiwan. J Oral Pathol Med 24: 450-453

Li X, Lee NK, Ye YW, Waber PG, Schweitzer C, Cheng QC, Nisen PD (1994) Allelic loss at chromosomes 3p, 8p, 13q, and 17p associated with poor prognosis in head and neck cancer. J Natl Cancer Inst 86: $1524-1529$

Olayioye MA, Neve RM, Lane HA, Hynes NE (2000) The ErbB signaling network: receptor heterodimerization in development and cancer. $E M B O$ J 19: $3159-3167$

Parker SL, Tong T, Bolden S, Wingo PA (1996) Cancer statistics. CA Cancer J Clin 46: $5-27$

Pfeiffer P, Nexo E, Bentzen SM, Clausen PP, Andersen K, Rose C (1998) Enzyme-linked immunosorbent assay of epidermal growth factor receptor in lung cancer: comparisons with immunohistochemistry, clinicopathological features and prognosis. Br J Cancer 78: 96-99

Robert F, Ezekiel MP, Spencer SA, Meredith RF, Bonner JA, Khazaeli MB, Saleh MN, Carey D, LoBuglio AF, Wheeler RH, Cooper MR, Waksal HW (2002) Phase I study of anti-epidermal growth factor receptor antibody cetuximab in combination with radiation therapy in patients with advanced head and neck cancer. J Clin Oncol 19: $3234-3243$

Salomon DS, Brandt R, Ciardiello F, Normanno N (1995) Epidermal growth factor-related peptides and their receptors in human malignancies. Crit Rev Oncol Hematol 19: 183-232

Shanmugaratnam K (1991) Histological typing of tumours of the upper respiratory tract and ear. International Histological Classification of Tumours, 2nd edn. Berlin: Spring-Verlag

Shin DM, Donato NJ, Perez-Soler R, Shin HJC, Wu JY, Zhang P, Lawhorn K, Khuri FR, Glisson BS, Myers J, Clayman G, Pfister D, Falcey J, Waksai H, Mendelsohn J, Hong WK (2001) Epidermal growth factor receptortargeted therapy with C225 and cisplatin in patients with head and neck cancer. Clin Cancer Res 7: 1204-1213

Simon MA (2000) Receptor tyrosine kinases: specific outcomes from general signals. Cell 103: $13-15$

Slaughter DP, Southwick HW, Smejkal W (1953) 'Field cancerization' in oral stratified squamous epithelium. Clinical implications of multicentric origin. Cancer 6: $963-968$

Storkel S, Reichert T, Reiffen KA, Wagner W (1993) EGFR and PCNA expression in oral squamous cell carcinomas-a valuable tool in estimating the patient's prognosis. Eur J Cancer B Oral Oncol 29B: $273-277$ 
Van Dyke DL, Worsham MJ, Benninger MS, Krause CJ, Baker SR, Wolf GT, Drumheller T, Tilley BC, Carey TE (1994) Recurrent cytogenetic abnormalities in squamous cell carcinomas of the head and neck region. Genes Chromosomes Cancer 9: $192-206$

Vikram B (1994) Changing patterns of failure in advanced head and neck cancer. Arch Otolaryngol Head Neck Surg 110: 564-565

Vogelstein B, Fearon ER, Hamilton SR, Kern SE, Preisinger AC Leppert M, Nakamura Y, White R, Smits AM, Bos JL (1988) Genetic alterations during colorectal-tumor development. $N$ Engl J Med 319: $525-532$

Vokes EE, Weichselbaum RR, Lippman SM, Hong WK (1993) Head and neck cancer. $N$ Eng J Med 328: $184-194$

Werkmeister R, Brandt B, Joos U (2000) Clinical relevance of erbB-1 and -2 oncogenes in oral carcinomas. Oral Oncol 36: 100-105

Widschwendter A, Tonko-Geymayer S, Welte T, Daxenbichler G, Marth C, Doppler W (2002) Prognostic significance of signal transducer and activator of transcription 1 activation in breast cancer. Clin Cancer Res 8 : $3065-3074$

Wong DYK, Chang KW, Chen CF, Chang RCS (1990) Characterization of two new cell lines-OC1 and OC2. J Oral Maxilofac Surg 48: 385-390

Xia W, Lau YK, Zhang HZ, Xiao FY, Johnston DA, Liu AR, Li L, Katz RL, Hung MC (1999) Combination of EGFR, HER-2/neu, and HER-3 is a stronger predictor for the outcome of oral squamous cell carcinoma than any individual family members. Clin Cancer Res 5: 4164-4174 